\title{
Welcome to Gastroenterology Insights
}

\author{
Alessandro Granito ${ }^{1, *}$ and Julio Plaza-Diaz ${ }^{2,3,4, *}$ \\ 1 Alma Mater Studiorum Università di Bologna, 40136 Bologna, Italy \\ 2 Children's Hospital of Eastern Ontario Research Institute, Ottawa, ON K1H 8L1, Canada \\ 3 Department of Biochemistry and Molecular Biology II, School of Pharmacy, University of Granada, \\ 18071 Granada, Spain \\ 4 Instituto de Investigación Biosanitaria IBS.GRANADA, Complejo Hospitalario Universitario de Granada, \\ 18014 Granada, Spain \\ * Correspondence: alessandro.granito@unibo.it (A.G.); jrplaza@ugr.es (J.P.-D.); Tel.: +34-958241599 (J.P.-D.)
}

Received: 18 September 2020; Accepted: 18 September 2020; Published: 19 September 2020

It is with great pleasure that we announce to you that MDPI has been in charge of the publication of Gastroenterology Insights since 20 July 2020. Gastroenterology Insights was launched by PAGEPress in 2009 and was indexed by ESCI in 2015 [1].

Gastroenterology Insights is an online-only, international, open-access, peer-reviewed journal that publishes scientific papers about gastrointestinal diseases. Manuscripts dealing with original, basic science research, biology, epidemiology, and clinical research involving all gastrointestinal and liver diseases are welcome. Articles on the pancreas and biliary content are also welcome. Gastroenterology Insights publishes original articles, editorials, perspectives, reviews, brief reports, and case reports. As an online, open-access journal supported by MDPI, all articles accepted after peer review in Gastroenterology Insights will be published online shortly thereafter and made immediately available, viewable by anyone globally for free.

I see Gastroenterology Insights as an exciting and interesting open-access journal that will develop into an influential, widely read part of the scientific literature. Now the Editorial Office and Editorial Board are working closely to increase the visibility and impact of this journal. To demonstrate the significant contribution of Gastroenterology Insights in the field of liver disease diagnosis and therapy, a Special Issue, Fatty Liver Syndrome [2], edited by the Editorial Board member Dr. Yoshio Sumida, is open for submissions. More interesting projects on liver and gastrointestinal diseases are forthcoming.

We believe that Gastroenterology Insights has the potential to serve its community well and become a leading platform for gastroenterologists. Together with the help of authors and reviewers, we aim to develop Gastroenterology Insights into an indispensable, high quality, and easily accessible source of information for gastroenterology-related professionals, nutrition professionals, and beyond. We look forward to tracking the cutting-edge research in this area, and to receiving your manuscripts, and sincerely hope that the authors enjoy publishing with us.

\section{References}

1. Gastroenterology Insights Homepage. Available online: https://www.pagepress.org/journals/index.php/gi/ index (accessed on 27 July 2020).

2. Fatty Liver Syndrome. Available online: https://www.mdpi.com/journal/gastroent/special_issues/FLS (accessed on 18 September 2020).

(C) 2020 by the authors. Licensee MDPI, Basel, Switzerland. This article is an open access article distributed under the terms and conditions of the Creative Commons Attribution (CC BY) license (http://creativecommons.org/licenses/by/4.0/). 